\title{
The effects of strain rate and temperature on commercial acrylic artist paints aged one year to decades
}

\author{
Eric W.S. Hagan • Maria N. Charalambides • Christina R.T. Young • \\ Thomas J. S. Learner
}

Received: date / Accepted: date

\begin{abstract}
Acrylic artist paints are viscoelastic composites containing a high molecular-weight copolymer, pigment and a variety of additives. The glass transition temperature of the latex binder is typically slightly below ambient conditions, giving mechanical properties that are strongly dependent on strain rate and temperature. In previous work, the viscoelastic behaviour of custom-formulated latex artist paints was reported for films with known volume fractions of pigment using data from uniaxial tensile tests at different strain rates and temperatures. Secant Young's modulus and failure strain mastercurves were constructed for each film through time-temperature superposition (TTS), allowing predictions beyond the experimental timescale at a selected reference temperature. A similar analysis is now presented for a small set of commercial artist paints tested at ages of one year and 27 years. Experimental
\end{abstract}

Funding for this research was provided by Tate, the Deborah Loeb Brice Foundation and the Natural Sciences and Engineering Research Council of Canada (NSERC).

\section{E.W.S. Hagan}

Preservation Services Division, Canadian Conservation Institute, 1030 Innes Road, Ottawa ON, K1B 4S7, Canada

Tel.: +1 613-998-3721 x224

Fax: +1 613-998-4721

E-mail: eric.hagan@canada.ca

M.N. Charalambides

Department of Mechanical Engineering, Imperial College London, South Kensington Campus, London SW7 2AZ, UK

\section{C.R.T. Young}

Department of Conservation and Technology, The Courtauld Institute of Art, Somerset House, Strand, London WC2R ORN, UK

T.J.S. Learner

The Getty Conservation Institute, 1200 Getty Center Drive, Suite 700. Los Angeles, CA 90049-1684, USA shift factor values are reported with fits to the Arrhenius, WLF and Vogel Fulcher (VF) equations, along with a comparison to published data for acrylic polymers. The tensile results highlight a spectrum of properties that acrylic paints may exhibit-brittle glass to hyperelastic - depending on the conditions during deformation. Strong similarities are shown between products from different manufacturers, and the findings suggest a high degree of stability with age. A method for predicting failure as a function of strain rate and temperature is also presented, and the methodology gives a framework for investigating other artist materials and the factors influencing their mechanical properties.

Keywords Artist Paints · Viscoelastic · TimeTemperature Superpostion · Failure Criteria

\section{Introduction}

\subsection{Mechanical testing of artist paints}

Much of the present knowledge surrounding the mechanical properties of artist paints comes from the body of research by Mecklenburg and coworkers [1-7]. Tensile data are published for oil, alkyd and acrylic artist paints, primarily as a function of temperature, humidity and age. The main focus of their work was the characterisation of equilibrium response at low rates of deformation. This led to a better understanding of the effects of fluctuating temperature and humidity in the museum environment, where tight tolerances come at high cost. The knowledge was then used to suggest relaxing the range for environmental control in museums and galleries, and achieve a practical balance of preservation and cost. More recently, Tantideeravit et al [8] have also 
predicted fatigue crack initiation times in years for various environmental conditions including ordinary and extreme histories that paintings may experience in museum and conservation settings.

The influence of strain rate appeared as a topic of concern during the International Conference on the Packing and Transportation of Paintings in 1991 [9]. This meeting included estimates of material response to strain rate and temperature [10], and provided tensile test data at different speeds for painting materials $[1,2]$. In later work, stress relaxation measurements were used to show the relative effectiveness of different lining treatments for oil paintings on canvas [11, 12]. Small strains were rapidly applied to model painting specimens, and stress was recorded over a period of milliseconds to several days under different environmental conditions. More recently, the viscoelastic properties of latex artist paints were investigated using custom formulations with controlled pigment content [13-15]. The effects of pigment concentration and geometry were shown over a large timescale using uniaxial tensile tests to failure. These data were compared to micromechanics models for composites [15], and used to calibrate a non-linear viscoelastic model that showed potential for finite element analysis (FEA) of stress in paintings [13].

The present work expands on past mechanical testing of commercial artist paints by focusing in greater depth on the effects of time and temperature. Emphasis is given to acrylics; however, the methods are applicable to many other painting materials. Previous research has shown that acrylic paints are time-dependent materials, exhibiting characteristic viscoelastic properties [13-16]. A technique for studying this form of material behavior is dynamic mechanical analysis (DMA), where the relationship between sinusoidal stress and strain is measured during temperature or frequency sweeps. Ormsby et al [16] used DMA to examine the effects of temperature, humidity and accelerated ageing on acrylic artist paints. In the present work, uniaxial tensile testing was applied since the time dependent failure strains were of interest for assessing failure criteria. A challenge with this approach is that a greater amount of experimental time and sample material is required. Test films included one-year-old artist paints and an acrylic ground. Two samples of 27-year-old paint films were also donated by Mecklenburg [17], allowing the opportunity to simultaneously investigate the effects of age on materials of related composition. When possible, it is valuable to examine naturally aged paint samples due to the complications that may arise during accelerated methods.

\subsection{Ageing characteristics}

The long-term stability of artist and conservation treatment materials is often estimated through accelerated ageing experiments at elevated temperature and light intensity. A practical advantage of this approach is that it provides useful data in a short period of time, while a possible disadvantage is the generation of physical and chemical processes not present under ambient conditions. Consider the thermal aging of a latex paint film, which may increase coalescence of the binder, evaporate film components and melt crystalline surfactant back into the film. All of these changes will affect mechanical properties and may not occur under ambient conditions. On the other hand, accelerated ageing can drive processes that provide a first approximation of mechanical response that would occur under natural conditions over an extended time.

The measurement of degradation by accelerated aging can be further complicated by heterogeneity through the material thickness. If damage occurs at the surface through photo-oxidation, then heterogenous aging can result, and mechanical testing of the bulk material may not show a change. Micro or nano-indentation of the surface, or through the thickness profile, could possibly provide more valuable information in this scenario. Heterogenous ageing may also result during a thermooxidative reaction if the thickness of the sample material is large [18] with slow oxygen diffusion. With paint films, this is less likely to occur due to the typical thin sample geometry $0.1 \mathrm{~mm}$ to $0.2 \mathrm{~mm}$ ).

Acrylic artist paints are considered highly stable materials; however, evidence of degradation is reported in the literature from experiments involving thermal and light-induced ageing. Learner et al [19] showed a lack of oxidation products after light aging, using fluorescent light filtered below 400nm to simulate museum conditions. Photo-ageing studies by Chiantore and Lazzari [20] on acrylic resins, and on paint films [21], showed that cross-linking and chain scission can occur with light exposure, and the form of damage appears to depend on the type of copolymer binder: chain scission for EA/MMA, and cross-linking for $n \mathrm{BA} / \mathrm{MMA}$ (via alkyl side chains). The light source used was a Xe-arc lamp filtered below $295 \mathrm{~nm}$, with a maximum temperature of $45^{\circ} \mathrm{C}$ on the samples. Scalarone et al [21] reported that the presence of pigment did not affect the degradation results unless ultraviolet (UV) energy was unfiltered in the $295 \mathrm{~nm}$ to $400 \mathrm{~nm}$ band. Smith [22] also studied the photo-ageing of non-pigmented films of a $n \mathrm{BA} / \mathrm{MMA}$ copolymer commonly used to formulate artist paints. Exposure to light from a Xenon arc lamp through reg- 
ular glass (filtering below approx. $330 \mathrm{~nm}$ ) showed increased cross-linking with light dose.

Most ageing studies focus on chemical analysis of degradation products, while mechanical testing is less common. The correlation with mechanical properties is important since it provides an indicator of the physical significance of a chemical change. Ormsby et al [16] provide one of the few mechanical studies of aged acrylic paint films using DMA. Photo-ageing with daylight fluorescent lamps (UV filtered) to a light dose of $40 \mathrm{Mlx} \cdot \mathrm{h}$ did not cause an observable change in the bulk film properties; however, changes were observed after thermal ageing at $60{ }^{\circ} \mathrm{C}$ for 16 weeks for some products.

\section{Materials and Methods}

\subsection{Sample Materials}

Acrylic latex artist paints were cast on polyester film and allowed to naturally age for one year prior to testing. The purpose of the initial ageing period was to ensure adequate coalescence of the paint binder, evaporation of volatile additives, and migration of surfactants [23-27]. Additional films of 27-year-old artists acrylic paints prepared by Mecklenburg [17] were included as a subset of the materials. The method of preparing these films was similar to the current approach. Table 1 provides a summary of the test materials indicating manufacturer, pigment type and age at the time of testing.

One day prior to analysis, the paint films were removed from the plastic substrate, and cut in $60 \times 6 \mathrm{~mm}$ rectangular strips. Paper tabs were then bonded to the ends of each specimen with cyanoacrylate adhesive, leaving a $40 \mathrm{~mm}$ gauge length. The tabs provided rigid sections for gripping the samples, while minimizing slippage and stress concentrations during clamping. The prepared samples were placed in small enclosures with silica gel buffering at $50 \% \mathrm{RH}$ overnight to equilibrate moisture content.

The thickness of each specimen was measured three times across the gauge length immediately before placement in the test chamber. An average value was used to calculate the initial cross-sectional area, and the resulting stress during deformation. Film thickness was in the range of $0.1 \mathrm{~mm}$ to $0.2 \mathrm{~mm}$ across the entire sample set.

\subsection{Apparatus}

Uniaxial tensile tests were performed with a universal testing machine (Instron, 4301) at four crosshead speeds: $0.05,0.5,5$ and $50 \mathrm{~mm} / \mathrm{min}$. Tests were repeated
Table 1 List of latex paint samples giving manufacturer, age, and abbreviation used in subsequent tables.

\begin{tabular}{lll}
\hline Product & Abreviation & Age (y) \\
\hline Golden latex (no pigment) & Binder & 1 \\
Golden $\mathrm{TiO}_{2}$ & ${\text { Gldn } \mathrm{TiO}_{2}}$ & 1 \\
Golden raw umber & Gldn R. U. & 1 \\
Liquitex ground & Lqtx gnd. & 1 \\
Liquitex burnt umber & Lqtx B.U. & 27 \\
Speedball raw umber & Spdbll R.U. & 27 \\
\hline
\end{tabular}

twice for each speed at temperatures -10, 0, 10, 20 and $30^{\circ} \mathrm{C}$ spanning the glass transition temperature at $T_{g} \approx 10^{\circ} \mathrm{C}$. This provided a total of twenty test conditions for each material, with 60 paint film specimens required for the replicates.

A custom-made environmental chamber was used to maintain the temperature set-point during tensile testing. The inner chamber was constructed with a $200 \mathrm{~W}$ thermoelectric assembly (TE Tech., CP-200) mounted to a die-cast aluminum enclosure with approximate dimensions of $345 \times 148 \times 82 \mathrm{~mm}$ (Hammond, 1590Z166). A calibrated PID controller (TE Technology, TC-720) was used to set the aluminum wall temperature for feedback control, and a thermistor was placed next to the sample to monitor air temperature at the test location. A small fan was also mounted inside the enclosure to circulate the air and increase temperature uniformity. The perimeter of the aluminum chamber was insulated, and an outer support structure was built to adapt to the Instron test machine. Ports were added to allow for installation of the grips, load-cell extension, sensor connections, and humidity control. An additional port in the door allowed tightening of the lower grip after the sample was conditioned to the environment in the chamber.

Humidity was controlled using a system constructed from a BasicX-24 microcontroller, serial LCD screen, opto-isolated relays (Panasonic, AQZ105), diaphragm pumps (Hargraves), and sensor (Vaisala, HMP50). A program was written for simple on/off control of the two pumps based on user set-point, which cycled air from the chamber through a desiccant column and water bubbler as required. The chamber was programmed for $50 \% \mathrm{RH}$, unless otherwise specified, for temperatures at $10^{\circ} \mathrm{C}$ and greater.

\section{Results and Discussion}

Load, extension and time were sampled during each tensile experiment, and used to construct stress-strain curves for the prescribed strain histories. From these data, a secant modulus, $E_{s}$, at $0.5 \%$ elongation, and 
strain to failure, $\epsilon_{f}$, were tabulated with corresponding initial strain rate, $R_{o}$, and time at failure, $t_{f}$, respectively. A brief overview of the stress-strain calculations is provided since the approach differs from previous mechanical studies on artist paints.

\subsection{Stress and Strain}

Three common measures of deformation are shown in Equations 1-3 using the sample gauge length, $l$, at time, $t$, and gauge length, $l_{o}($ at $t=0)$. The engineering (nominal) strain, $e$, is most often applied for small deformations, whereas true strain, $\epsilon$, is better suited for small to large extensions. The latter method accounts for increasing gauge length as the sample is stretched. The extension ratio, $\lambda$, is another common measure that is used primarily for elastomers [28]. In this study, the true strain was applied to all tensile data using Equation 3. Note that nominal and true strain converge as $e \longrightarrow 0$; therefore, the difference is negligible at small extensions (see Table 2).

$e=\left(l-l_{o}\right) / l_{o}=\Delta l / l_{o}$

$\lambda=l / l_{o}$

$\epsilon=\int_{l_{o}}^{l} \frac{\mathrm{d} l}{l_{o}}=\ln \left(l / l_{o}\right)$

There are also different ways to report stress in a tensile experiment. For small strains, the nominal stress, $s$, is calculated as

$s=P / A_{o}$,

where $P$ is the measured load on the sample, and $A_{o}$ is the initial cross-sectional area. Equation 4 underestimates stress at large strains since the cross-sectional area decreases as the sample is stretched. A correction is often applied using true stress

$\sigma=\lambda s$,

which accounts for the cross-sectional area decrease as a function of strain. The accuracy of Equation 5 relies on strain uniformity across the sample gauge length, and the assumption of constant volume during deformation (incompressibility). The incompressibility assumption requires a shear modulus that is much smaller than the bulk modulus, or similarly Poisson's ratio of 0.5. Ideally, the calculation of true stress would take into account the compressibility of the sample using the time dependent Poisson's ratio or shear modulus; however, this was beyond the scope of the project. Time-dependent moduli and Poisson's ratio are further discussed by Ferry [29] and Tschoegl [30] respectively.
Table 2 Comparison of strain rate and nominal strain with true strain for a tensile test at constant speed.

\begin{tabular}{lll}
\hline$\epsilon$ & $\left(R-R_{o}\right) / R_{o}, \%$ & $(e-\epsilon) / \epsilon, \%$ \\
\hline 0 & 0 & 0 \\
0.005 & -0.50 & 0.25 \\
0.010 & -1.0 & 0.50 \\
0.020 & -2.0 & 1.0 \\
0.050 & -4.9 & 2.5 \\
0.100 & -9.5 & 5.2 \\
0.200 & -18 & 11
\end{tabular}

The purpose of collecting tensile data at multiple temperatures and strain rates was to apply the timetemperature superposition principle (TTS) [29,31], and construct mastercurves of $E_{s}$ and $\epsilon_{f}$. This requires a measure of time for each of the parameters. The apparatus was not capable of performing constant strain rate experiments, where speed is increased accordingly during sample extension. Tests were therefore performed at constant speed, $V$, resulting in a strain rate decrease with time and strain according to

$R(t)=\frac{\mathrm{d} \epsilon(t)}{\mathrm{d} t}=\frac{V}{l_{o}+V t}$,

where

$\epsilon(t)=\ln \left(\frac{V t+l_{o}}{l_{o}}\right)$.

Taking the limit of Equation 6 as $t$ approaches zero gives the initial strain rate

$R_{o}=\lim _{t \rightarrow 0} R(t)=\frac{V}{l_{o}}$.

The inverse of the initial strain rate, $1 / R_{o}$, was used as the time parameter in seconds for plotting secant modulus, $E_{s}$. For failure strain, $\epsilon_{f}$, the time at failure, $t_{f}$, was tabulated at each value and the average strain rate was used. Table 2 shows the percentage decrease of strain rate versus the applied true strain for a constant speed tensile test. Deviation from $R_{o}$ is less than $10 \%$ for strains below 0.1 , indicating approximately constant strain rate for the strains of primary interest. As a point of reference, many artists' oil paints fail at strains less than 0.05 in an ambient environment when deformed at low strain rate $[2,7]$.

\subsection{Stress-Strain Curves}

Figure 1 shows a representative set of tensile stressstrain curves using the 27 year-old Liquitex burnt umber test data. The material exhibits a strong time dependent response, where stress increases with increasing strain rate and/or decreasing temperature. Note 


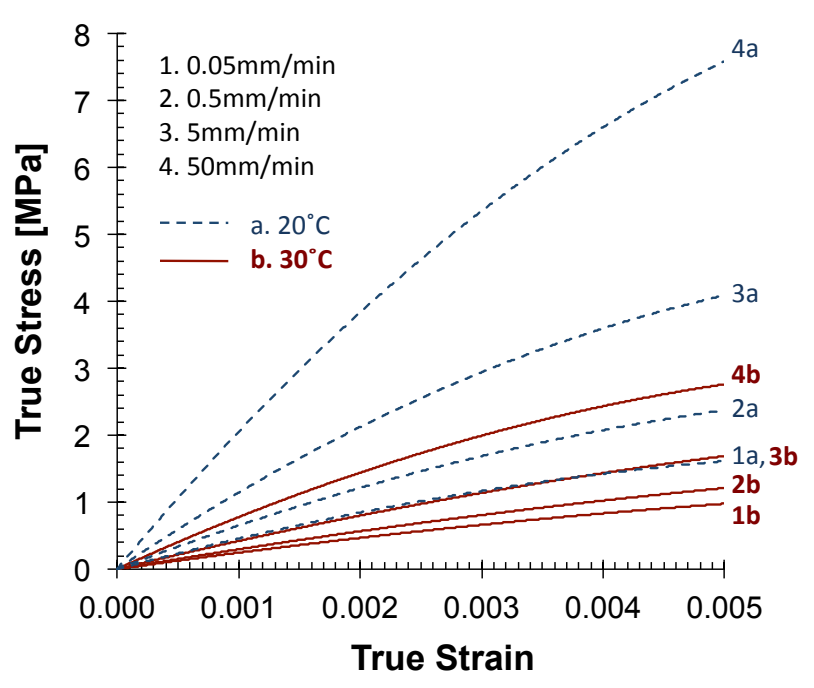

Fig. 1 Stress-strain curves for 27 year-old Liquitex burnt umber paint films at two temperatures and four crosshead speeds.

that the curve for $0.05 \mathrm{~mm} / \mathrm{min}$ at $20^{\circ} \mathrm{C}$ overlaps with $5 \mathrm{~mm} / \mathrm{min}$ at $30^{\circ} \mathrm{C}$. The effect of a strain rate change by two orders of magnitude is similar to changing temperature by $10^{\circ} \mathrm{C}$. The curves highlight the viscoelastic nature of the material, and show potential for applying time-temperature superposition (TTS).

\subsection{Secant Modulus}

For an elastic-plastic material, the Young's modulus, $E$, is the slope of the stress-strain curve prior to plastic deformation, and by definition it is unaffected by strain rate. Stress varies with time at fixed strain for a viscoelastic material; therefore, a relaxation modulus, $E(t)$, is more appropriately defined. Determining $E(t)$ experimentally is a challenge since it is the ratio of time varying stress, $\sigma(t)$, to a small step (i.e. instantaneous) strain, $\epsilon_{o}$, given by the relationship

$E(t)=\frac{\sigma(t)}{\epsilon_{o}}$.

It is possible to measure part of the relaxation modulus by performing a stress relaxation experiment where a rapid initial strain is applied, followed by a period of constant strain where the stress is monitored. Values of $E(t)$ are typically taken at times significantly greater than the ramp duration. In this investigation, a secant modulus, $E_{s}$ at $\epsilon=0.005$ was used as an alternate method to summarise tensile data at small strains. The value of $E_{s}$ was tabulated from each stress-strain curve along with the corresponding initial strain rate, $R_{o}$, calculated from Equation 8. The tensile experiments were performed at constant speed; therefore, strain rate decreased during extension of the sample according to the function $R(t)$ in Equation 6. At $\epsilon=0.005$, the strain rate decreases by only $0.5 \%$ from the initial value of $R_{o}$.

Figure 2 summarises the $E_{s}$ values for six materials at the different test speeds and temperatures on a log$\log$ plot. The time axis is given as $\log \left(1 / R_{o}\right)$ to show decreasing $E_{s}$ with increasing time. The glass transition temperature, $T_{g}$, of artists acrylic paints is typically near $10^{\circ} \mathrm{C}$ when measured with differential scanning calorimetry (DSC), indicating that these data span the approximate range of $T_{g} \pm 20^{\circ} \mathrm{C}$. Each plot highlights the response of the respective film through the transition from glassy to rubbery behavior. The largest modulus change occurs for the latex binder since it lacks the binder constraint given by rigid pigment particles. The curves become compressed and shift upwards when pigment is present, giving an effect similar to cross-linking. For the artist paints and the acrylic ground, $E_{s}$ varies by approximately two orders of magnitude between rubbery and glassy regions. The umber paints and ground material contain platelet-shaped particles, which affect the modulus to a greater extent than spherical particles. The modulus enhancement from the pigment depends on the volume fraction, geometry and orientation of the particles [14,15,32-34]. Particle size, and adhesion between the particles and matrix, may also play a role.

For each material, the curves at $-10^{\circ} \mathrm{C}$ begin to flatten as the test speed increases (short times) and the acrylic binder becomes glassy. Higher strain rates and/or lower temperature will not have a strong effect on the modulus at this point, and the value is considered the instantaneous modulus, $E_{o}$. Figure 2 also shows that the modulus approaches a lower limit at $30^{\circ} \mathrm{C}$ for the slowest test speed, which indicates the rubbery material response near equilibrium leading to $E_{e}$. A factor that was not investigated in this study was the influence of physical aging [35] when the material is quenched below $T_{g}$. This will have an impact on the measured $E_{s}$ values, which are expected to increase with time spent at low temperature before the test is initiated. All experiments were performed after approximately $15 \mathrm{~min}$ equilibration at the low temperatures, which is significantly longer than the duration of the experiment.

Time-Temperature Superposition The TTS principle is a valuable method for summarising modulus data for a viscoelastic material, and predicting the response beyond the experimental timescale: (1) at strain rates higher than the limits of the instrument; (2) at very low strain rates, not practical due to the time required for measurement. To illustrate the method, Figure 3a 

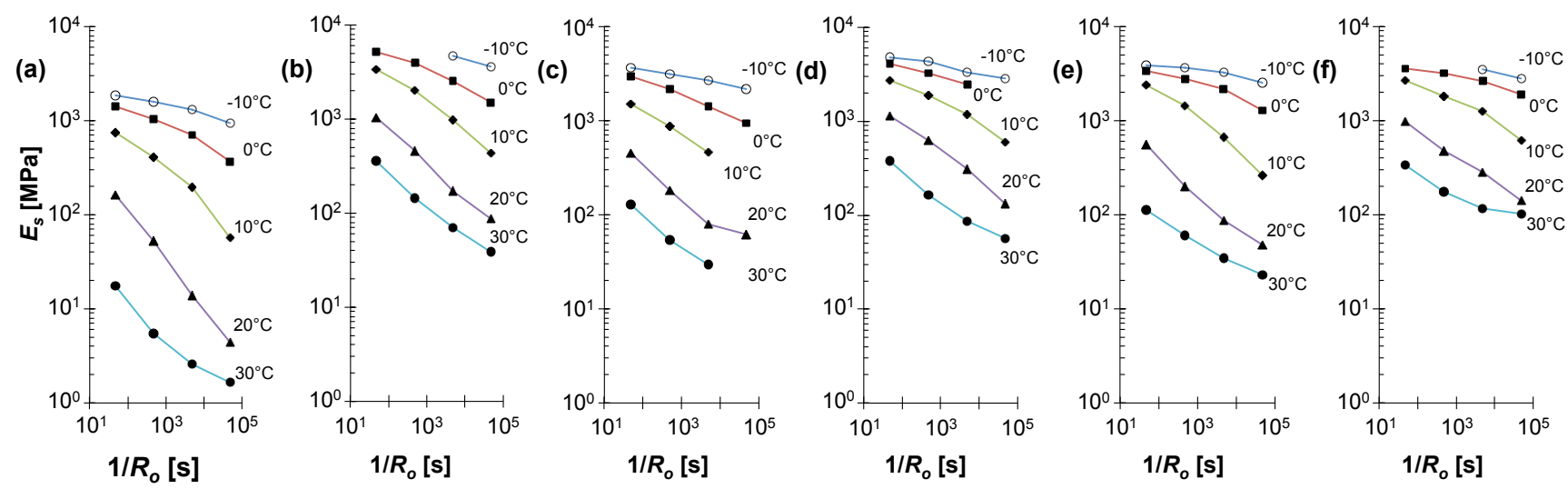

Fig. 2 Secant modulus summary at each test speed and temperature: a. latex binder with no pigment (1y); b. Liquitex ground $(1 \mathrm{y})$; c. Golden titanium white (1y); d. Golden raw umber (1y); e. Speedball raw umber (27y); f. Liquitex burnt umber (27y).

presents a set of modulus curves at three temperatures. Figure $3 \mathrm{~b}$ shows two of the curves shifted horizontally along the time axis to overlap with data at a selected reference temperature, $T_{\text {ref }}$. The modulus data are now reduced to $T_{r e f}$, and the mastercurve indicates the material response over a larger timescale for a single temperature. Arrows show the original experimental window, and the extended regions where data was previously absent.

On a log-time scale, the horizontal shift is defined as $\log \left(1 / a_{T}\right)$, where $a_{T}$, is the shift factor. Superposition is often applied to sinusoidal data from dynamic mechanical analysis (DMA), where log frequency is shifted by $\log \left(a_{T}\right)$. The time axis in Figure 3 is given in units of seconds from the inverse of strain rate, and a horizontal shift of $\log \left(1 / a_{T}\right)$ gives

$\log \left(\frac{1}{R_{o} a_{T}}\right)=\log \left(\frac{1}{R_{o}}\right)+\log \left(\frac{1}{a_{T}}\right)$

as the reduced time at $T_{\text {ref }}$. It is also possible to plot these curves with the $\mathrm{x}$-axis showing reduced strain rate as $\log \left(R a_{T}\right)$ in place of the inverse.

Time-temperature superposition was applied to secant modulus data in Figure 2 using Equation 10, and the results are summarised in Table 3 for $T_{\text {ref }}=10^{\circ} \mathrm{C} \approx$ $T_{g}$. These data were used to determine the WLF and Vogel Fulcher parameters for $T \geq T_{g}$. The WLF equation

$\log \left(a_{T}\right)=-\frac{C_{1}\left(T-T_{r e f}\right)}{C_{2}+\left(T-T_{r e f}\right)}$

relates the shift factor to temperature using parameters $C_{1}$ and $C_{2}$. Common values are $C_{1}^{g}=17.44$ and $C_{2}^{g}=51.6 \mathrm{~K}$ for many polymers, where the $g$ superscript denotes $T_{\text {ref }}=T_{g}$ [31]. The equivalent Vogel Fulcher equation gives

$\eta(T)=\eta_{\infty} \exp \frac{T_{b}}{T-T_{\infty}}$,
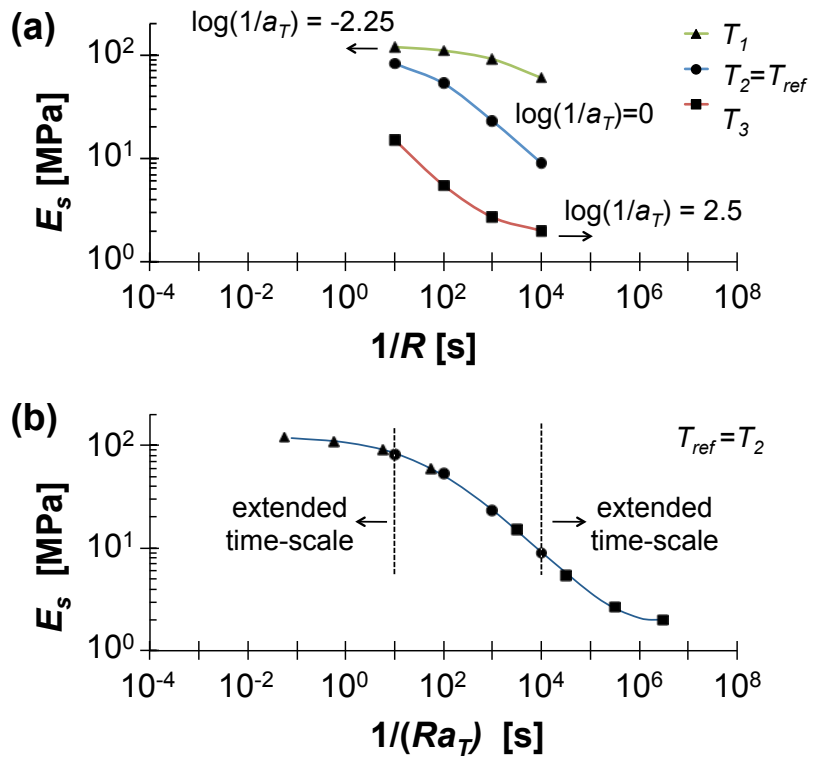

Fig. 3 Illustration of time-temperature superposition: a. experimental data collected within a limited time-scale; b. Modulus master curves constructed by shifting curves along the time axis to overlay fixed data at the reference temperature.

where $\eta_{\infty}$ is the high temperature viscosity [36], $T_{b}$ is related to the structural strength of the system, and $T_{\infty}$ is the temperature where $\eta$ is infinite (Vogel temperature) [37]. The viscosity (or relaxation time) ratio between $T$ and $T_{\text {ref }}$ provides the shift factor

$a_{T}=\frac{\eta(T)}{\eta\left(T_{\text {ref }}\right)}=\frac{\exp \left(\frac{T_{b}}{T-T_{\infty}}\right)}{\exp \left(\frac{T_{b}}{T_{r e f}-T_{\infty}}\right)}$,

which simplifies to

$\log \left(a_{T}\right)=-\frac{T_{b} / \ln (10)}{T_{r e f}-T_{\infty}}+\frac{T_{b} / \ln (10)}{T-T_{\infty}}$. 
The VF equation is commonly written in the three parameter form [38],

$\log \left(a_{T}\right)=A+\frac{B}{T-T_{\infty}}$

where

$$
\begin{aligned}
& A=-\frac{B}{T_{\text {ref }}-T_{\infty}} \\
& B=\frac{T_{b}}{\ln (10)} .
\end{aligned}
$$

Comparison with the WLF equation gives $A=-C_{1}$ and $B=C_{1} C_{2}$. Two additional parameters that are derived from the WLF/VF equations [36] are the dynamic fragility

$m=T_{g}\left(\frac{C_{1}^{g}}{C_{2}^{g}}\right)=\frac{T_{b} / T_{g}}{\ln (10)\left(1-T_{\infty} / T_{g}\right)^{2}}$,

and the apparent activation energy

$E_{g}=\ln (10) R T_{g} m$.

The values of $E_{g}$ and $m$ relate to the rate of deviation of Equation 15 from the Arrhenius equation

$\log \left(a_{T}\right)=\frac{E_{a}}{\ln (10) R}\left(\frac{1}{T}-\frac{1}{T_{\text {ref }}}\right)$

at $T_{g}$, where $E_{a}$ is the activation energy, and $R$ is the gas constant. A comparison of Equations 15 and 19 indicates that the VF equation is equivalent to the Arrhenius form when $T_{\infty}=0 \mathrm{~K}$ and $E_{g}=E_{a}$, which gives $B=E_{a} /[\ln (10) R]$ and $m=E_{a} /\left[\ln (10) R T_{g}\right]$. Deviation of VF from Arrhenius increases as $T_{\infty}$ increases, and with subsequent variation of $B$. Qin and MacKenna [36] describe these concepts with an analysis of data indicating a general relationship of $E_{g} \approx 0.006 T_{g}^{2}-35$ for polymeric materials. The estimate predicts $E_{g} \approx$ $445 \mathrm{~kJ} / \mathrm{mol}$ for the paint films in this study where $T_{g}=$ $283 \mathrm{~K}$.

Table 4 summarises the WLF, VF and Arrhenius parameters from fitting Equations 11 and 19 to $\log \left(a_{T}\right)$ data in Table 3 . Values of $E_{a}$ for the Arrhenius equation are in the range of 221 to $264 \mathrm{~kJ} / \mathrm{mol}$ for the set of materials. Accuracy is limited by three data points and a narrow temperature range of $20^{\circ} \mathrm{C}$ for curve fits above and below $T_{g}$. The fits for WLF/VF were therefore performed under two conditions: 1 . unconstrained, solving for $C_{1}^{g}$ and $C_{2}^{g}$; and 2. constrained, solving for $C_{1}^{g}$ with $C_{2}^{g}=50 \mathrm{~K}$. The latter condition is based on the general observation that $C_{2}^{g} \approx 50 \mathrm{~K}$ for many polymers [29]. Apparent activation energy is 304 to $399 \mathrm{~kJ} / \mathrm{mol}$ for the unconstrained fit (slightly lower than the prediction of $445 \mathrm{~kJ} / \mathrm{mol}$ ), and dynamic fragility values fall within the range of values in a review by Qin and
Table 3 Experimental values of $\log \left(a_{T}\right)$ versus temperature using $T_{\text {ref }}=283 \mathrm{~K}$.

\begin{tabular}{llllll}
\hline Product & $\begin{array}{l}263 \mathrm{~K} \\
-10{ }^{\circ} \mathrm{C}\end{array}$ & $\begin{array}{l}273 \mathrm{~K} \\
0{ }^{\circ} \mathrm{C}\end{array}$ & $\begin{array}{l}283 \mathrm{~K} \\
10^{\circ} \mathrm{C}\end{array}$ & $\begin{array}{l}293 \mathrm{~K} \\
20^{\circ} \mathrm{C}\end{array}$ & $\begin{array}{l}303 \mathrm{~K} \\
30^{\circ} \mathrm{C}\end{array}$ \\
\hline Latex binder & 3.4 & 1.8 & 0 & -2.1 & -3.9 \\
Golden $\mathrm{TiO}_{2}$ & 3.7 & 2.0 & 0 & -1.8 & -3.3 \\
Golden R.U. & 3.1 & 1.8 & 0 & -2 & -3.7 \\
Liquitex gnd. & 3.2 & 1.5 & 0 & -2 & -3.3 \\
Speedball R.U. & 3.3 & 1.8 & 0 & -2.2 & -3.8 \\
Liquitex B.U. & 3.5 & 2.1 & 0 & -2.3 & -3.9 \\
\hline
\end{tabular}

McKenna [36] at 64 to 79 for the films. The WLF parameters are significantly higher for the non-pigmented latex and Golden products, while the values for 27 yearold films are in the more typical range. Similarly, the values of $B$ are high for the first three films in the list, and $T_{\infty}$ appears low in comparison to the typical value of $T_{g}-50 \mathrm{~K}$. The fits with the constraint of $C_{2}^{g}=50 \mathrm{~K}$ show less variation of $C_{1}^{g}$ and $B$, with an average of 12.6 and 630 respectively. The values of $E_{a}$ and $m$ are slightly higher with the constraint added; however, they are still within the same general magnitude.

Comparisons with data for pure homopolymers are complicated by the fact that the latex paints are acrylic copolymers containing a variety of additives and a pigment phase. The one-year-old commercial films in this study are most likely $n \mathrm{BA} / \mathrm{MMA}$ copolymers, while 27 year-old films are expected to contain a EA/MMA copolymer [39]. The ratio of the monomers is formulated to give a glass transition near $10^{\circ} \mathrm{C}$, and the molecular weight, $M_{w}$, is typically very high for latex paint binders. In an analysis of acrylic artist paints from the 1990's, Chiantore et al [39] determined average $M_{w}$ in the range of 93,600 to 696,000 . Difficulties were encountered when dissolving the copolymer into solution with tetrahydrofuran, and it was noted that the molecular weights may be higher than measured. In order to provide an approximate comparison with related materials, Table 5 lists a series of WLF/VF parameters for acrylic homopolymers from literature sources with $C_{1}, C_{2}$ and $A$ adjusted to $T_{r e f}=T_{g}$ using Equation 16 and the described VF-WLF correlation. Values of $M_{w}$ are also given where available. Andreozzi et al [40] have published VF parameters for $\mathrm{p}(\mathrm{EA})$, showing an increase of $B$ and $T_{\infty}$ with increasing $M_{w}$. Their results also indicate a decrease of $E_{g}$ and $m$ with $M_{w}$ for the materials. As a general observation, the WLF and VF values for the constrained fits in Table 4 show good correlation with those in Table 5 . The Table 4 calculations of dynamic fragility and $E_{g}$ are also of comparable magnitude.

Figure 5 gives the secant modulus master curves of the one-year-old films constructed using $\log \left(a_{T}\right)$ values 


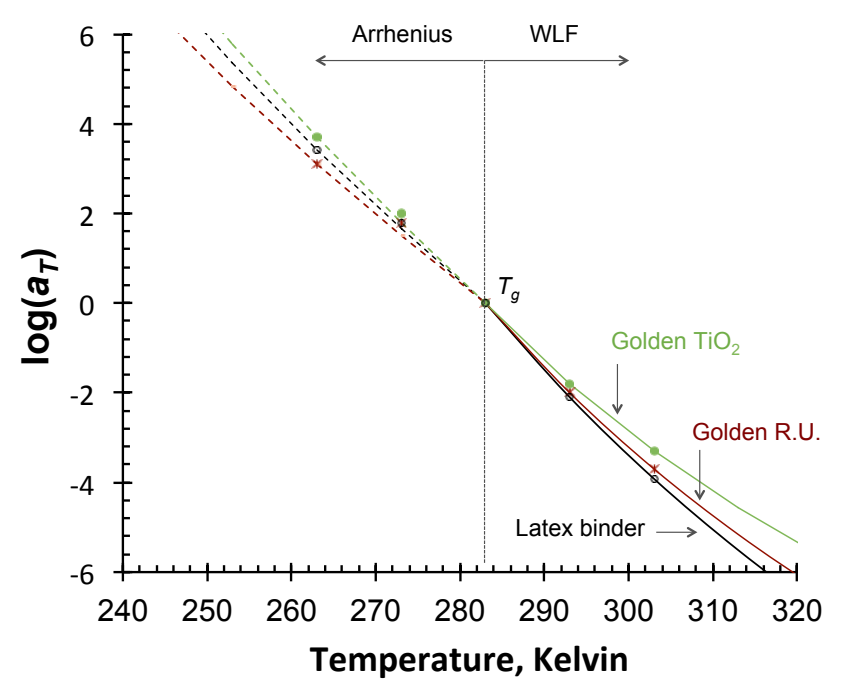

Fig. 4 Comparison of $\log \left(a_{T}\right)$ experimental values at $T_{\text {ref }}=$ $283 \mathrm{~K}$ with WLF (unconstrained, see Table 4) and Arrhenius curve fits above and below $T_{g}$ respectively.

Table 4 Comparison of WLF, Vogel-Fulcher and Arrhenius fit parameters for $\log \left(a_{T}\right)$ data in Table 3 using $T_{r e f}=283 \mathrm{~K}$.

\begin{tabular}{|c|c|c|c|c|c|c|c|}
\hline \multirow[b]{2}{*}{ Product } & \multicolumn{2}{|l|}{ Arh. } & \multicolumn{2}{|c|}{ WLF } & \multicolumn{2}{|c|}{ V-F } & \multirow[b]{2}{*}{$m$} \\
\hline & $\begin{array}{l}\begin{array}{l}E_{a} \\
\mathrm{~kJ}\end{array} \\
\mathrm{~mol}\end{array}$ & $\begin{array}{l}\begin{array}{l}E_{g} \\
\mathrm{~kJ}\end{array} \\
\mathrm{~mol}\end{array}$ & $C_{1}^{g}$ & $\begin{array}{l}C_{2}^{g} \\
\mathrm{~K}\end{array}$ & $B$ & $\begin{array}{l}T_{\infty} \\
\mathrm{K}\end{array}$ & \\
\hline \multicolumn{8}{|c|}{ Unconstrained fits } \\
\hline Binder & 244 & 347 & 29 & 130 & 3815 & 153 & 64 \\
\hline Gldn $\mathrm{TiO}_{2}$ & 264 & 399 & 20 & 100 & 1977 & 183 & 74 \\
\hline Gldn R.U. & 221 & 334 & 25 & 113 & 2786 & 170 & 62 \\
\hline Lqtx gnd & 221 & 304 & 9 & 33 & 288 & 250 & 56 \\
\hline Spdbll R.U. & 235 & 401 & 14 & 53 & 742 & 230 & 74 \\
\hline Lqtx B.U. & 249 & 430 & 13 & 46 & 586 & 237 & 79 \\
\hline Average & 240 & 366 & 15 & 65 & 997 & 218 & 68 \\
\hline \multicolumn{8}{|c|}{ Constrained $C_{2}^{g}=50 \mathrm{~K}$} \\
\hline Binder & - & 405 & 13.2 & 50 & 660 & 233 & 75 \\
\hline Gldn $\mathrm{TiO}_{2}$ & - & 353 & 11.5 & 50 & 575 & 233 & 65 \\
\hline Gldn R.U. & - & 383 & 12.5 & 50 & 625 & 233 & 71 \\
\hline Lqtx gnd & - & 353 & 11.5 & 50 & 575 & 233 & 65 \\
\hline Spdbll R.U. & - & 405 & 13.2 & 50 & 660 & 233 & 75 \\
\hline Lqtx B.U. & - & 420 & 13.7 & 50 & 685 & 233 & 78 \\
\hline Average & - & 386 & 12.6 & 50 & 630 & 233 & 71 \\
\hline
\end{tabular}

in Table 3 adjusted to $T_{r e f}=20^{\circ} \mathrm{C}$. Each curve shows a transition from glassy behavior at very short times (high strain rate) to rubbery at very long times (low strain rate). The inflection occurs at a similar time, which suggests a similar $T_{g}$ between products. The influence of the inorganic particles is now more clearly shown than Figure 2. Films with pigment or filler have higher overall modulus values due to the strain enhancement provided by the rigid particles. This is observed by the upward shift to higher $E_{s}$ values at all times.

The titanium white paint film has a low modulus relative to the other products, which is likely due to the near spherical geometry of the particles. Earth pig-

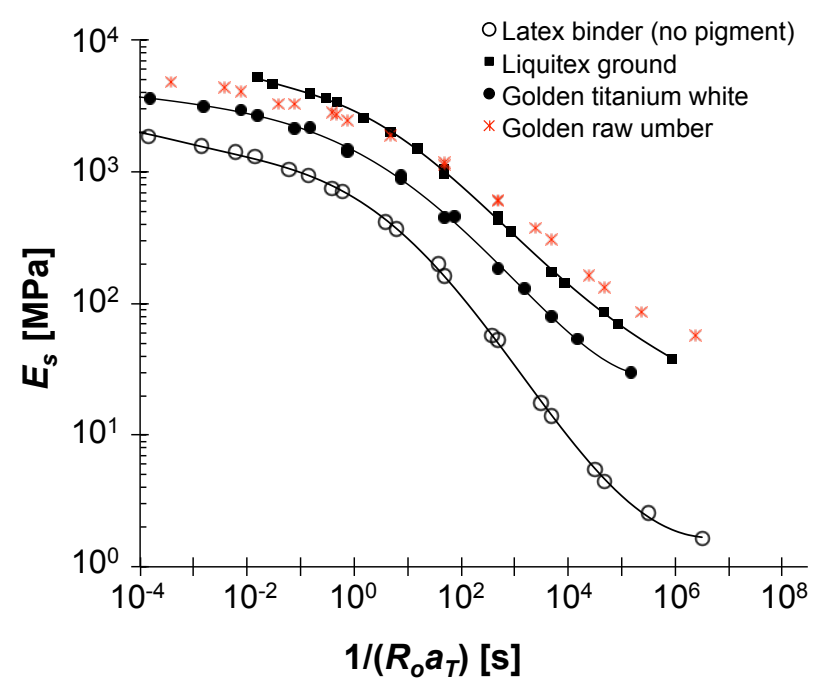

Fig. 5 Secant modulus master curves at $20^{\circ} \mathrm{C}$ for one-yearold paint films and the non-pigmented latex.

ments (umber, ochre, sienna) contain clays, which are expected to give a stronger enhancement effect due to their platelet geometry [15]. The influence of particle shape, and differences in concentration, are likely the main factors contributing to differences in film modulus. The inorganic volume fraction for the titanium white product was estimated at $33 \%$ in a previous study [42] using a combination of gas pycnometer measurements for density, thermo-gravimetric analysis (TGA), and a simple rule of mixtures calculation. Values were not estimated for films containing other pigment types.

The acrylic ground used in this study was selected from a range of commercial products examined in earlier work $[42,43]$. It was found that this particular product was relatively stiff and less extensible within a set of similar materials. Energy dispersive x-ray (EDX) analysis of the ground indicated a variety of inorganic compounds including $\mathrm{TiO}_{2}, \mathrm{CaCO}_{3}$, kaolin and likely talc. Similar rule-of-mixtures approximations with TGA data suggested a higher volume fraction of inorganic particles in the ground than in other products. Unfortunately, the mixture of various types of inorganic compounds made it difficult to provide an accurate value for comparison. The higher $E_{s}$ values for the acrylic ground relative to the titanium white paint are again likely due to differences in concentration and particle shape.

A similar plot of $E_{s}$ is given in Figure 6, showing a comparison of curves for the one-year and 27 yearold paint films. The results are similar, which provides some indication that the acrylic binder has not changed significantly with age. Four individual points are also shown from a re-examination of tensile data collected by Mecklenburg et al $[4,17]$. Pigments are indicated by 
Table 5 WLF and Vogel Fulcher literature values for acrylate and methacrylate polymers with adjustment to $T_{r e f}=T_{g}$ where necessary.

\begin{tabular}{|c|c|c|c|c|c|c|c|c|c|c|}
\hline \multirow[b]{2}{*}{ Polymer } & \multirow[b]{2}{*}{$\begin{array}{l}T_{g} \\
\mathrm{~K}\end{array}$} & \multicolumn{2}{|c|}{ WLF } & \multicolumn{3}{|c|}{ Vogel-Fulcher } & \multirow[b]{2}{*}{$\begin{array}{l}E_{g} \\
\mathrm{~kJ} / \mathrm{mol}\end{array}$} & \multirow[b]{2}{*}{$\mathrm{m}$} & \multirow[b]{2}{*}{$\begin{array}{l}M_{w} \\
\mathrm{~g} / \mathrm{mol}\end{array}$} & \multirow[b]{2}{*}{ Source / Notes } \\
\hline & & $C_{1}^{g}$ & $\begin{array}{l}C_{2}^{g} \\
\mathrm{~K}\end{array}$ & $A$ & $B$ & $\begin{array}{l}T_{\infty} \\
\mathrm{K}\end{array}$ & & & & \\
\hline \multicolumn{11}{|c|}{ acrylates } \\
\hline $\mathrm{p}(\mathrm{MA})$ & 280 & 14.2 & 36.8 & -14.2 & 521 & 244 & 579 & 108 & $3,920,000$ & [38] Full fit \\
\hline $\mathrm{p}(\mathrm{MA})$ & 280 & 12.8 & 21.8 & -12.8 & 279 & 259 & 884 & 165 & $3,920,000$ & [38] Fit for $T_{g} \geq T \leq T_{c}$ \\
\hline $\mathrm{p}(\mathrm{MA})$ & 276 & 16.7 & 54.0 & -16.7 & 900 & 222 & 450 & 85 & - & [29] Source data at $\bar{T}_{r e f}=324 \mathrm{~K}$ \\
\hline $\mathrm{p}(\mathrm{EA})$ & 257 & 11.5 & 32.1 & -11.5 & 367 & 225 & 452 & 92 & $3,230,000$ & [38] Full fit \\
\hline $\mathrm{p}(\mathrm{EA})$ & 257 & 11.4 & 32.4 & -11.5 & 370 & 225 & 447 & 91 & $3,230,000$ & [38] Fit for $T_{g} \geq T \leq T_{c}$ \\
\hline $\mathrm{p}(\mathrm{EA})$ & 253 & 12.2 & 51.0 & -12.2 & 622 & 202 & 293 & 61 & 150,000 & [40] PEA20R \\
\hline $\mathrm{p}(\mathrm{EA})$ & 249 & 12.2 & 48.0 & -12.2 & 586 & 201 & 304 & 64 & 9,600 & [40] PEA18R \\
\hline $\mathrm{p}(\mathrm{EA})$ & 231 & 12.6 & 37.0 & -12.6 & 466 & 194 & 348 & 79 & 1,200 & [40] PEA15R \\
\hline $\mathrm{p}(\mathrm{BA})$ & 224 & 11.7 & 35.1 & -11.7 & 412 & 189 & 321 & 75 & $4,610,000$ & [38] Full fit \\
\hline $\mathrm{p}(\mathrm{BA})$ & 224 & 11.0 & 29.8 & -11.0 & 328 & 194 & 355 & 83 & $4,610,000$ & [38] Fit for $T_{g} \geq T \leq T_{c}$ \\
\hline $\mathrm{p}(\mathrm{BA})$ & 224 & 12.4 & 50.0 & -12.4 & 619 & 175 & 238 & 56 & 14,700 & {$[41]$} \\
\hline \multicolumn{11}{|c|}{ methacrylates } \\
\hline $\mathrm{p}(\mathrm{MMA})$ & 376 & 18.1 & 67.3 & -18.1 & 1216 & 309 & 727 & 101 & $2,050,000$ & [38] Full fit \\
\hline $\mathrm{p}$ (MMA) & 376 & 17.4 & 14.6 & -17.4 & 253 & 361 & 3228 & 449 & $2,050,000$ & [38] Fit for $T_{g} \geq T \leq T_{c}$ \\
\hline $\mathrm{p}$ (MMA) & 388 & 32.2 & 80.0 & -32.2 & 2576 & 308 & 1160 & 156 & - & [29] Conventional type \\
\hline $\mathrm{p}(\mathrm{EMA})$ & 344 & 13.2 & 58.5 & -13.2 & 775 & 286 & 513 & 78 & $2,930,000$ & [38] Full fit \\
\hline $\mathrm{p}(\mathrm{EMA})$ & 344 & 12.5 & 51.0 & -12.5 & 636 & 293 & 555 & 84 & $2,930,000$ & [38] Fit for $T_{g} \geq T \leq T_{c}$ \\
\hline $\mathrm{p}(\mathrm{EMA})$ & 335 & 17.8 & 65.0 & -17.8 & 1157 & 270 & 588 & 92 & - & [29] Source data at $\bar{T}_{\text {ref }}=373 \mathrm{~K}$ \\
\hline $\mathrm{p}(\mathrm{BMA})$ & 305 & 12.3 & 56.3 & -12.3 & 694 & 249 & 390 & 67 & $2,870,000$ & [38] Full fit \\
\hline $\mathrm{p}(\mathrm{BMA})$ & 305 & 11.2 & 46.4 & -11.2 & 520 & 259 & 430 & 74 & $2,870,000$ & [38] Fit for $T_{g} \geq T \leq T_{c}$ \\
\hline $\mathrm{p}(\mathrm{BMA})$ & 300 & 17.0 & 97.0 & -17.0 & 1645 & 203 & 301 & 52 & - & [29] Source data at $\bar{T}_{r e f}=373 \mathrm{~K}$ \\
\hline
\end{tabular}

abbreviation: titanium white (Ti); burnt sienna (BS), cobalt blue $(\mathrm{CB})$, and cadmium yellow $(\mathrm{CY})$. These four products were tensile tested in 1991 under ambient conditions using a strain rate that was several orders of magnitude slower than the lowest value in this study. Each of the four points falls in the equilibrium range that mastercurves from TTS appear to approach at longer times. Testing at higher temperatures than $30{ }^{\circ} \mathrm{C}$ and applying TTS may provide similar findings at long times; however, the melting of surfactant crystals may affect results by plasticising the film.

\subsection{Failure Strains}

The latex paint films can respond as a brittle glass or an elastomeric material depending on the combination of strain rate and temperature imposed during deformation. The brittle-ductile transition is evident in failure strain data from the tensile experiments, showing a change of more than two orders of magnitude across the $T_{g}$. The application of TTS is usually restricted to small strain tensile data; however, Smith [44-47] showed the method applied to the ultimate properties of rubber materials. A similar approach was taken in this work, where failure strain mastercurves were constructed by shifting the average strain rate, $R_{a}$, from the constant

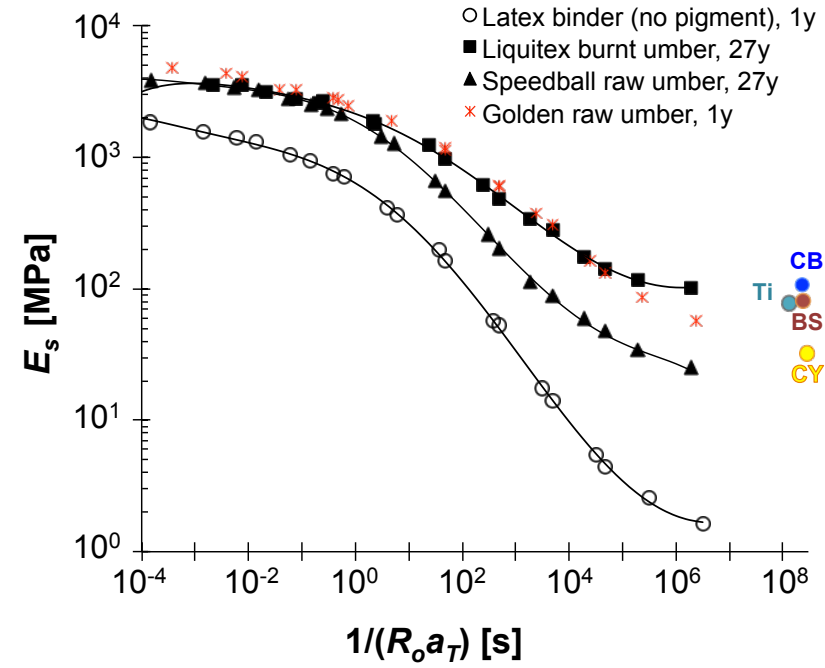

Fig. 6 Secant modulus master curves at $20^{\circ} \mathrm{C}$ for one-yearold and 27 year-old paint films. Single data points are also shown from an evaluation of low strain-rate tensile experiments published by Mecklenburg et al $[4,17]$.

speed test. This was was calculated as

$R_{a}=\frac{\epsilon_{f}}{t_{f}}$

where $\epsilon_{\mathrm{f}}$ and $t_{f}$ are the strain and time at failure respectively. The experimental shift factors in Table 3 (adjusted to $T_{r e f}=20^{\circ} \mathrm{C}$ ) were applied in a manner 
similar to Equation 10 using

$\log \left(R_{a} a_{T}\right)=\log \left(R_{a}\right)+\log \left(a_{T}\right)$

The use of $R_{a}$ gives a slight correction for the strain rate decrease during the experiment, particularly when the sample extends to large strains in the rubbery region. Similar plots were also constructed using $R_{o}$ and the differences between the two curves were subtle. The use of $R_{o}$ and $R_{a}$ for the abscissa are illustrated in Figure 7 for the non-pigmented latex binder material. The points are shifted slightly apart at high failure strains, and they converge as failure strains decrease at high strain rate.

Figure 7 also gives a comparison of failure strain mastercurves that complement the modulus data in Figure 5. As a general observation, values of $\epsilon_{f}$ lower than 0.01 indicate that the material is highly brittle, while those above 0.1 indicate that the material is highly extensible. The area beneath each set of points is the predicted 'safe region' where failure does not occur in the initially stress-free material if it is subjected to the respective strains and rates of deformation. The horizontal lines highlight several strain values that are within the typical range of interest for artist paints. Following one of the lines of constant strain from left to right indicates that the binder must reach the strain faster than any of the pigmented films in order for failure to occur. The non-pigmented binder is therefore less sensitive to failure, while the acrylic ground is the most sensitive. The acrylic ground is, however, relatively extensible under many conditions when compared to a traditional oil ground. For example, Mecklenburg [6, 7] gives tensile data for 10 to 15 year-old films of lead white in linseed oil, which fail at a nominal strain of approximately $e=0.05$. A broader comparison with similar data for oil paints would offer valuable perspective on the differences between traditional and modern artist paint media.

A similar plot in Figure 8 shows a strong similarity of failure response for films at different ages. This provides further indication of binder stability with age, since it is expected that a significant level of deterioration by cross-linking or chain scission would alter the shape of the curve, and its location on the time axis. Unfortunately, a failure curve is not available for the 27 year-old products at an earlier age to verify that a small change has not occurred in the film behaviour over time. An ideal experiment on naturally aged films would involve tracking the material response over many years either with DMA for small strain response, or tensile testing to failure.

It is also possible to reconstruct failure data to show the influence of strain rate and temperature on a sin-

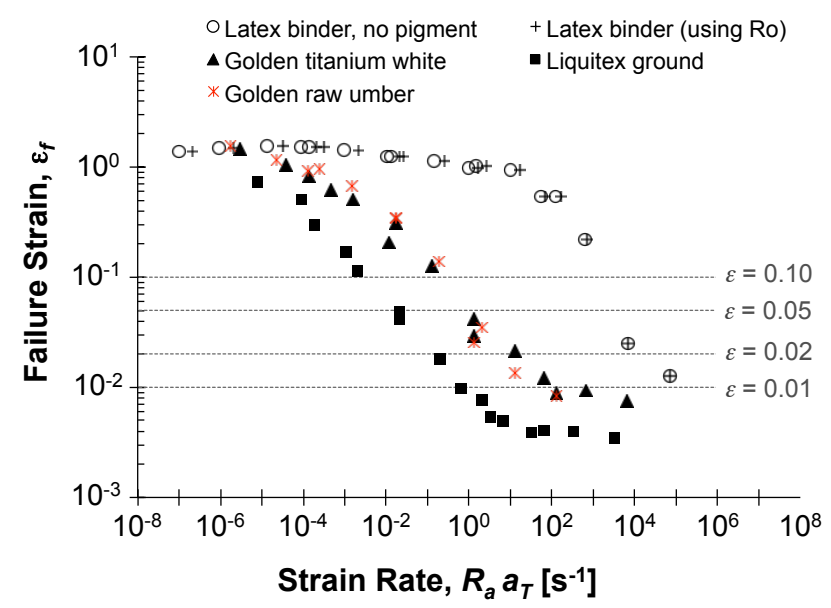

Fig. 7 Failure strain master curves for the one-year-old paint films and non-pigmented latex at $20^{\circ} \mathrm{C}$. Additional data points are shown for the non-pigmented latex using $R_{o}$ in place of $R_{a}$ for reference.

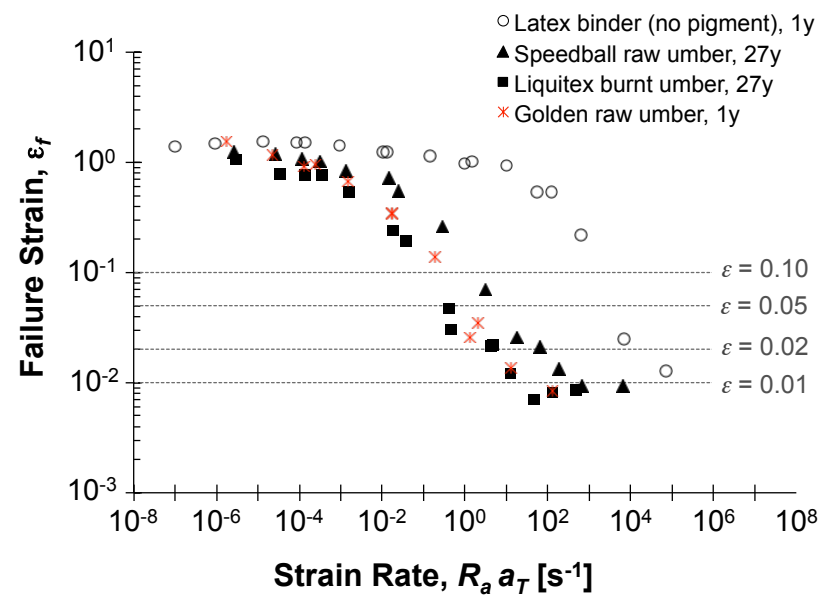

Fig. 8 Failure strain master curves for the one-year-old and 27 year-old paint films at $20^{\circ} \mathrm{C}$.

gle isometric plot. As an example of this approach, a polynomial curve was fit through the Liquitex ground failure points in Figure 7. Values were then interpolated at three selected values of $\epsilon_{f}(0.005,0.01$, and 0.05$)$, and the shift factors were used to adjust to different temperatures. The results from this series of calculations are presented in Figure 9, showing three isometric curves with combinations of strain rate and temperature that predict failure for the ground material. Following a vertical line at a fixed temperature highlights the increased strain rate that is required for the material to fail at the lower strain values. Conversely, a horizontal path with increasing temperature shows the increasing failure strain at a fixed strain rate. This form of plot may be useful for predicting safe regions for paintings; however, complicating factors such as stresses arising from different thermal expansion coefficients of layered ma- 


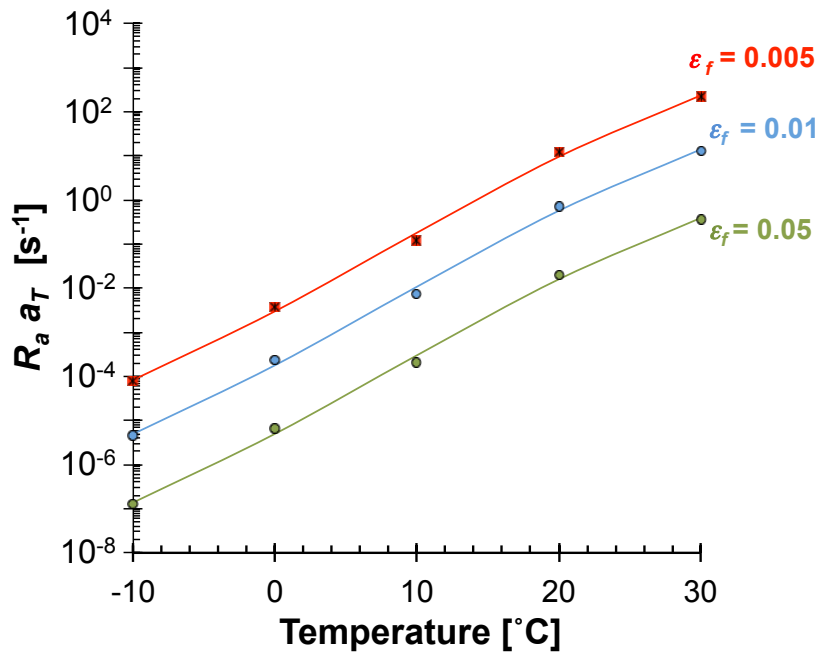

Fig. 9 Isometric plot of failure strains as a function of strain rate and temperature for the Liquitex acrylic ground.

terials, and the unknown strain history of the painting are important considerations.

\subsection{Effect of Relative Humidity}

The results presented in Figures 5-8 are strictly for samples equilibrated at $50 \% \mathrm{RH}$ since it is a common target for museums and galleries. The influence of varying levels of relative humidity is a fundamental concern for paintings preservation and deserves further attention. In an investigation with DMA, Ormsby et al [16] highlighted the effect of $\mathrm{RH}$ on the $\tan (\delta)$ peak and modulus of artists' acrylic paints at constant frequency. The influence of $\mathrm{RH}$ on tensile properties was also studied by Erlebacheret al [3] using a single strain rate.

Figure 10 shows a sorption isotherm for the nonpigmented acrylic latex in the current study, and a similar curve for the Golden titanium white film with moisture content calculated for the binder phase. This change of moisture content with $\mathrm{RH}$ has an effect on the stress relaxation response of an acrylic paint film, which made it necessary to equilibrate moisture content and control RH during tensile experiments. A detailed investigation of moisture content effects was beyond the scope of this work; however, preliminary results are given in Figure 11 showing partial mastercurves that were constructed for the latex binder conditioned to $5 \% \mathrm{RH}$ without pigment and with $38 \% \mathrm{TiO}_{2}$ by volume. The loss of moisture appears to increase the $T_{g}$ of the binder as the curve shifts to the right on the time axis for the non-pigmented film. The application of time-moisture superposition $[48,49]$ may add further value to this type of data for artist paint media, which

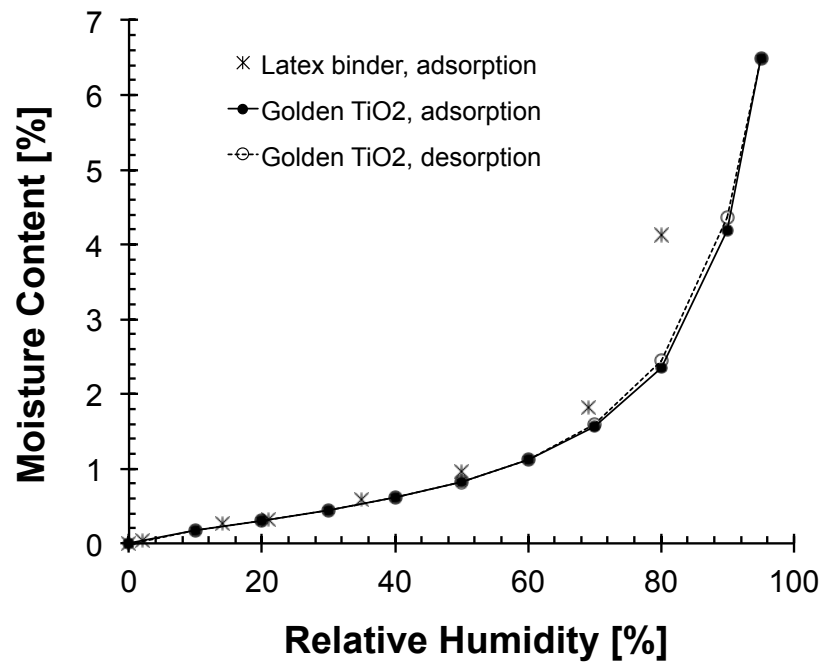

Fig. 10 Sorption isotherms at $23^{\circ} \mathrm{C}$ for the non-pigmented latex binder, and the organic phase of the Golden titanium white paint.

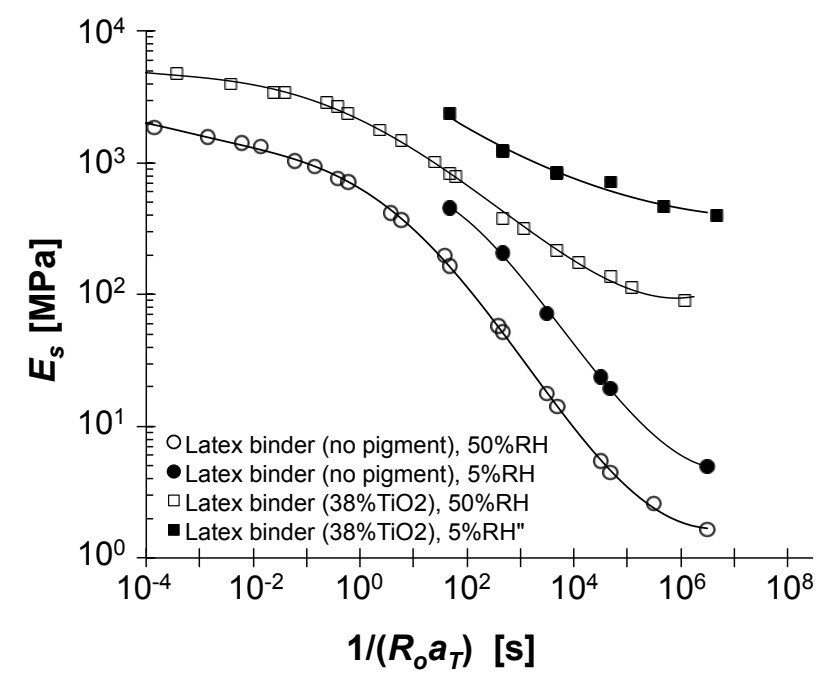

Fig. 11 Secant modulus at $20^{\circ} \mathrm{C}$ for the latex binder with $0 \%$ and $38 \% \mathrm{TiO}_{2}$ conditioned at two relative humidity levels.

is an area for further investigation. This may prove difficult, however, if changes in moisture content alter the equilibrium modulus. As an example, the curves for the pigmented film appear to differ by more than a simple shift along the time axis.

\section{Conclusions}

The mechanical behaviour of artists acrylic paints was measured over a broad range of strain rate and temperature to the point of failure. Time-temperature superposition was applied to secant modulus and failure strains for each of the six test films, and the WLF/VF 
and Arrhenius equations were fit to experimental values of $\log \left(a_{T}\right)$. The Arrhenius equation gave activation energy in the range of 221 to $264 \mathrm{~kJ} / \mathrm{mol}$ below $T_{g}$. Considerable variation was observed in the WLF/VF parameters, which is possibly a result of the small number of data points or differences in paint formulation. Fits with the constraint of $C_{2}^{g}=50 \mathrm{~K}$ showed less variation and closer correlation of parameters with published data for acrylic polymers. The modulus master curves each showed a similar point of inflection on the time axis, and the effect of inorganic particles was an overall increase of $E_{s}$ at all times. There was a high degree of similarity between the one-year and 27 year-old films present in modulus data. Subtle differences were likely due to variations in pigment concentration and particle geometry. The identification of small changes over time would require monitoring a single film over many years with a similar test method.

The construction of $\epsilon_{f}$ master curves by TTS provided a method for predicting failure as a function of strain rate and temperature, when the rate of deformation does not vary significantly during extension. Failure strains transitioned from very small $\left(\epsilon_{f}<0.01\right)$ in the glassy region to very large $\left(\epsilon_{f}>1\right)$ in the rubbery regime. This is characteristic of the brittle-ductile transition of an amorphous polymer across the glass transition. The Liquitex ground was suspected to have the highest volume fraction of inorganic material, and particles with low aspect ratio (talc and kaolin). This material showed the lowest failure strains of the examined films; however, it remained highly extensible under many conditions when compared to a traditional oil ground. Mecklenburg [6,7] gives tensile data for a lead white oil ground showing a nominal strain to failure of 0.05 at an age of 10 to 15 years. The failure response of the 27 year-old acrylic paint films was also very similar to one-year-old products, which was consistent with findings reported for secant modulus and the shift factors. Finally, an approach for interpreting failure strain data was presented using an isometric graph of strain rate versus temperature. This may provide a useful method for presenting failure data for viscoelastic artist paint media in future work.

Acknowledgements The authors sincerely thank Tate, the Deborah Loeb Brice foundation and the Natural Sciences and Engineering Research Council of Canada (NSERC) for sponsoring this project. We also greatly appreciate the sharing of samples and data files by Marion Mecklenburg at the Smithsonian Institution.

\section{References}

1. M.F. Mecklenburg, C.S. Tumosa, in Art in transit: Studies in the transport of paintings, ed. by M.F. Mecklenburg (National Gallery of Art, Washington, 1991), pp. 137-171

2. M.F. Mecklenburg, C.S. Tumosa, in Art in Transit: Studies in the Transport of Paintings, ed. by M.F. Mecklenburg (National Gallery of Art, Washington, 1991), pp. 173-216

3. J.D. Erlebacher, E. Brown, M.F. Mecklenburg, C.S. Tumosa, in Materials Research Society Symposium Proceedings, vol. 267, ed. by P.B. Vandiver, J.R. Druzik, G.S. Wheeler, I.C. Freestone (Materials Research Society, Pittsburgh, 1992), vol. 267, pp. 359-370

4. M.F. Mecklenburg, C.S. Tumosa, J.D. Erlebacher, Polymer Preprints 35(2), 297 (1994)

5. M.F. Mecklenburg, C.S. Tumosa, ASHRAE journal 41(4), 77 (1999)

6. M.F. Mecklenburg, in Preprints of the International Conference on Painting Conservation: Canvases - Behaviour, Deterioration and Treatment, ed. by M.C. Ahusti, M. Martin Rey, V. Guerola Blay (Universitat Politècnica de València, 2005), pp. 119-155

7. M.F. Mecklenburg, C.S. Tumosa, D. Erhardt, in Materials Research Society Symposium: Materials Issues in Art and Archaeology VII, vol. 852, ed. by P.B. Vandiver, J.L. Mass, A. Murray (Materials Research Society, Warrendale, 2005), vol. 852, pp. 13-24

8. S. Tantideeravit, M.N. Charalambides, D.S. Balint, C.R.T. Young, Engineering Fracture Mechanics 112, 41 (2013)

9. M.F. Mecklenburg, Art in Transit: Studies in the Transport of Paintings (National Gallery of Art, Washington, 1991)

10. S. Michalski, in Art in Transit: Studies in the Transport of Paintings, ed. by M.F. Mecklenburg (National Gallery of Art, Washington, 1991), pp. 223-248

11. S. Michalski, D. Daly Hartin, in Preprints of the ICOM Committee for Conservation, 11th Triennial Meeting, ed. by J. Bridgland (James and James Ltd., London, 1996), pp. $288-296$

12. D. Daly Hartin, E.W.S. Hagan, S. Michalski, M. Choquette, in Preprints of the ICOM Committee for Conservation, 16th Triennial Meeting, ed. by J. Bridgland (Critério, Almada, Portugal, 2011), pp. 1-9

13. E.W.S. Hagan, M.N. Charalambides, C.R.T. Young, T.J.S. Learner, S. Hackney, Mechanics of TimeDependent Materials 13(2), 149 (2009)

14. E.W.S. Hagan, M.N. Charalambides, C.R.T. Young, T.J.S. Learner, S. Hackney, Progress in Organic Coatings 69(1), 73 (2010)

15. E.W.S. Hagan, M.N. Charalambides, C.R.T. Young, T.J.S. Learner, S. Hackney, Polymer 52(7), 1662 (2011)

16. B. Ormsby, G. Foster, T. Learner, S. Ritchie, M. Schilling, Journal of Thermal Analysis and Calorimetry 90(2), 503 (2007)

17. M.F. Mecklenburg. Personal communication. Smithsonian Institution (2006)

18. M.C. Celina, Polymer Degradation and Stability 98(12), 2419 (2013)

19. T. Learner, O. Chiantore, D. Scalarone, in Preprints of the ICOM Committee for Conservation, 13th Triennial Meeting, vol. II, ed. by R. Vontobel (James and James Ltd., London, 2002), vol. II, pp. 911-919

20. O. Chiantore, M. Lazzari, Polymer 42(1), 17 (2001) 
21. D. Scalarone, O. Chiantore, T. Learner, in Preprints of the ICOM Committee for Conservation, 14th Triennial Meeting, vol. I, ed. by I. Verger (James and James Ltd., London, 2005), vol. I, pp. 350-357

22. G.D. Smith, in Modern Paints Uncovered, ed. by T.J.S. Learner, P. Smithen, J.W. Krueger, M.R. Schilling (Getty Conservation Institute, Los Angeles, 2008), pp. 236-246

23. J.L. Keddie, Materials Science and Engineering: R Reports 21(3), 101 (1997)

24. P.A. Steward, J. Hearn, M.C. Wilkinson, Advances in Colloid and Interface Science 86(3), 195 (2000)

25. E. Kientz, Y. Holl, Colloids and Surfaces a Physicochemical and Engineering Aspects 78(15), 255 (1993)

26. A. Tzitzinou, P.M. Jenneson, A.S. Clough, J.L. Keddie, J.R. Lu, P. Zhdan, K.E. Treacher, R. Satguru, Progress in Organic Coatings 35(1-4) (1999)

27. A.C. Hellgren, P. Weissenborn, K. Holmberg, Progress in Organic Coatings 35(1-4), 79 (1999)

28. L.R.G. Treloar, The Physics of Rubber Elasticity, 3rd edn. (Oxford University Press, Oxford, 1975)

29. J.D. Ferry, Viscoelastic Properties of Polymers, 3rd edn. (Wiley, New York, 1980)

30. N.W. Tschoegl, Mechanics of Time-Dependent Materials 1, 3 (1997)

31. M.L. Williams, R.F. Landel, J.D. Ferry, Journal of the American Chemical Society 77(14), 3701 (1955)

32. G.P. Tandon, G.J. Weng, Polymer Composites 5(4), 327 (1984)

33. B.E. Clements, E.M. Mas, Journal of Applied Physics 90(11), 5522 (2001)

34. E.M. Mas, B.E. Clements, Journal of Applied Physics 90(11), 5535 (2001)

35. L. Struik, Polymer Engineering and Science 17(3), 165 (1977)

36. Q. Qin, G.B. McKenna, Journal of Non-Crystalline Solids 352(28-29), 2977 (2006)

37. L. Dadug, Journal of Physics: Condensed Matter 12(46), $9573(2000)$

38. X. He, J. Wu, G. Huang, X. Wang, Journal of Macromolecular Science, Part B: Physics 50(1), 188 (2011)

39. O. Chiantore, D. Scalarone, T. Learner, International Journal of Polymer Analysis and Characterization 8(1), 67 (2003)

40. L. Andreozzi, V. Castelvetro, M. Faetti, M. Giordano, F. Zulli, Macromolecules 39(5), 1880 (2006)

41. L. Andreozzi, C. Autiero, M. Faetti, M. Giordano, F. Zulli, Journal of Physics: Condensed Matter 18(28), 6481 (2006)

42. B.A. Ormsby, E. Hagan, P. Smithen, T.J.S. Learner, in Preparation for Painting: The Artist's Choice and its Consequences, ed. by J. Townsend, T. Doherty, G. Heydenreich, J. Ridge (Archetype, London, 2008), pp. 163171

43. C.R.T. Young, E. Hagan, in Preparation for Painting: The Artist's Choice and its Consequences, ed. by J. Townsend, T. Doherty, G. Heydenreich, J. Ridge (Archetype, London, 2008), pp. 172-179

44. T.L. Smith, P.J. Stedry, Journal of Applied Physics 31(11), 1892 (1960)

45. T.L. Smith, ASTM Materials Science, Series 3, 60 (1962)

46. T.L. Smith, Journal of Polymer Science Part A: General Papers 1(12), 3597 (1963)

47. T.L. Smith, R.A. Dickie, Rubber Chemistry and Technology 42(5), 1257 (1969)

48. H.F. Brinson, L.C. Brinson, Polymer engineering science and viscoelasticity: an introduction (Springer, 2007)

49. R.D. Maksimov, V.P. Mochalov, Y.S. Urzhumtsev, Mechanics of Composite Materials 8(5), 1573 (1972) 